\title{
MARGINAL INTEGRITY OF GLASS CERAMIC LAMINATE VENEERS PRODUCED THROUGH DIFFERENT CAD/CAM MILLING PROTOCOLS: IN-VITRO STUDY
}

\author{
Carl Hany* and Maha Taymour*
}

\begin{abstract}
Statement of the problem: The conservative nature of the labial ceramic veneers necessitates minimum amount of tooth reduction with thin peripheral margins. Since construction time of restorations is becoming a determinant factor together with accuracy, the effect of three different $\mathrm{CAD} / \mathrm{CAM}$ milling protocols that depend on the time factor deserves to be assessed.

Purpose: The purpose of this investigation was to evaluate the effect of three different CAD/ CAM milling protocols; namely normal, fast, and two-step milling on the peripheral marginal accuracy of glass-ceramic laminate veneers.
\end{abstract}

Materials and Methods: A maxillary central incisor acrylic tooth was chosen to serve as a die for veneer construction. Acrylic tooth preparation was done to receive incisal feather edge design for the ceramic veneer. A total of thirty laminate veneer restorations were constructed from IPS e.max CAD glass ceramic using the CAD/CAM technology with three different milling protocols. The veneers were divided into the following groups according to the selected milling protocol; Group 1: Ten veneers constructed using the normal milling protocol, Group 2: Ten veneers constructed using the fast milling protocol, Group 3: Ten veneers constructed using the twostep milling protocol. The milled veneers were subjected to crystallization process according to manufacturer's instructions then they were checked on their corresponding die for proper adaptation and seating. For proper assessment of the vertical marginal gap, the veneers were fixed on the master die using one drop of adhesive placed centrally to stabilize the veneers in their place during the measuring procedure. The vertical marginal gap distance of each ceramic was measured using a stereomicroscope at magnification X45. The measurements were done along the peripheral circumference for all the veneer margins (mesial, distal, cervical and incisal). Measurement at each point was repeated five times. A digital image analysis system was used for assessing and evaluating vertical marginal gap width. The mean vertical marginal gap distance was calculated and then tabulated for the statistical analysis of the data.

* Associate Professor, Fixed Prosthodontics Department, Faculty of Dentistry. Cairo University. 
Results: Effect of milling protocol: The two-step milling protocol showed the statistically significant lowest mean marginal gap distance $(33.2 \pm 6.3 \mu \mathrm{m})$ while both the normal and fast milling protocols showed the statistically significant highest mean marginal gap distances with no statistically significant difference between them. ( $40 \pm 7.5 \mu \mathrm{m}$ and $41.2 \pm 4.9 \mu \mathrm{m}$ respectively) Effect of surface: The cervical surface recorded the statistically significant lowest mean marginal gap distance $(34 \pm 6.5 \mu \mathrm{m})$ while the distal surface recorded the highest mean marginal gap distance $(41.6 \pm 8.6 \mu \mathrm{m})$ with non-statistically significant difference from incisal $(37.2 \pm 4.6 \mu \mathrm{m})$ and mesial surface $(39.7 \pm 6.4 \mu \mathrm{m})$.

Conclusions: Within the limitations of this in-vitro study, the following conclusions were drawn: 1) Marginal discrepancy of all groups fell within the clinically acceptable value, thus the three milling protocols can be safely used. 2)Veneers fabricated using the two-step milling protocol exhibited the least marginal discrepancy among other experimental groups, thus it can be used as the protocol of preference if restoration accuracy is of utmost importance. 3) Since there was no significant difference between normal and fast milling protocols regarding marginal discrepancy, therefore fast milling can be recommended for veneer fabrication if chairside time is of prime importance in some cases. 4) Cervical marginal discrepancy was found to have the least value compared to other surfaces

\section{INTRODUCTION}

Ceramic laminate veneers are becoming now very popular conservative solution restoring many cases including diastemas, chipped and discolored teeth. Since its evolution, many materials have been used for its fabrication starting with normal feldspathic ceramics ${ }^{(1)}$. However, with the introduction of lithium disilicate ceramics in the dental market offering excellent esthetics in addition to high flexural strength as well as versatility in their construction technique (either CAD/ CAM or heat pressed), they became the most commonly recommended material for veneers fabrication. ${ }^{(2,3)}$

It is well known that the clinical longevity of any cemented restoration including laminate veneers depends on many factors mainly the marginal accuracy ${ }^{(4,5)}$. Marginal discrepancies between the prepared tooth structure and the restorations often lead to leakage of oral fluids beneath the restoration which in turn can cause dissolution of cement, recurrent caries, sensitivity and marginal discoloration. (6,7) In addition to this, marginal adaptation and fit of the veneers influence the resin cement thickness that significantly affects the shade and color of these thin restorations. ${ }^{(8-11)}$
Vertical distance between the preparation's finish line and the margin of the ceramic veneers is a common definition of vertical marginal gap. (12) Different methods have been introduced for its in vitro measurement as stereo, scanning and transmission electron microscopy, micro-computed tomography (micro-CT) or optical coherence tomography. ${ }^{(13)}$ Each of these methods has its pros and cons that dictate its usage in different situations.

Although various studies showed controversial results concerning the clinically acceptable marginal gap values, yet most of them agreed that a marginal gap between 100 and $120 \mu \mathrm{m}$ appears to be in the range of clinical acceptance. ${ }^{(14,15)}$

Since accuracy of dental restorations has been of prime importance for dental practitioners especially in the field of CAD/CAM restorations production, thus various attempts were made to focus on this aspect. The effect of the three basic steps involved in the $\mathrm{CAD} / \mathrm{CAM}$ procedure on accuracy of dental restorations has been previously addressed in many studies. For example some studies evaluated the different scanning procedures in terms of restorations fitting, ${ }^{(16,17)}$ while others dealt with the designing phase to improve the outcome of fixed prosthesis. 
(18) Regarding the third step which is the milling phase, previous researchers evaluated the trueness of available milling devices in the dental market. (19) They found that five axes milling machines yielded significantly better results than four axes milling machines in terms of restorations fitting. Other investigators compared marginal integrity of ceramic copings having different marginal angle designs fabricated by various $\mathrm{CAD} / \mathrm{CAM}$ systems. They concluded that the different milling processes used in their study had a significant effect on marginal chipping and accuracy of the ceramic restorations. ${ }^{(20)}$

Due to the increased awareness about the importance of chairside time reduction, thus $\mathrm{CAD} /$ CAM latest technologies were developed to provide not only an accurate restoration but also with fast construction technique as the time needed for restoration construction has become valuable to both the dentist and patient. ${ }^{(21)}$ One of these technologies was introduced within the recent softwares which enabled the practitioner to choose from various milling protocols namely the normal, fast and two step milling procedures. The normal milling option is the standard mode that can be used for all materials and indications. If desired, the milling process can be accelerated when using the fast milling option which reduces the grinding time by about $40 \%$ as claimed by the manufacturer, enabling the dentist to fit the restoration in a faster period. (22) In the two step milling procedure, the milling time is extended by around $50-60 \%$ as it involves 2 steps. ${ }^{(22)}$ First step is for removing excess material by fast mill followed by the second step where the final milling and details of the restoration are accomplished at a regular speed. This option is mainly indicated for milling thin and small restorations as veneers and inlays.

Up till now and according to the investigator's knowledge, the literature still lacks the point of research addressing the effect of different milling protocols on the marginal accuracy of laminate veneers. Thus this study was conducted to evaluate the effect of three different CAD/CAM milling protocols; namely normal, fast, and two-step milling on the peripheral marginal accuracy of glass-ceramic laminate veneers. The null hypothesis of the present investigation was that there would be no difference concerning the marginal accuracy among the three milling protocols

\section{MATERIAL AND METHODS}

A total of thirty laminate veneer restorations constructed from IPS e.max CAD glass ceramic were designed and fabricated in this study. The veneers were divided into three groups representing the different milling protocols; Group 1: Ten veneers constructed using the normal milling protocol, Group 2: Ten veneers constructed using the fast milling protocol. Group 3: Ten veneers constructed using the two-step milling protocol.

\section{I) Acrylic tooth preparation:}

A maxillary central incisor acrylic tooth of a Typodont model (NISSIN Dental Model, Koyoto, Japan) was chosen to serve as a die for veneer construction. The maxillary central incisor was scanned before preparation to serve as a biocopy reference of the unprepared acrylic tooth which aids in duplicating the original tooth anatomy during the subsequent CAD/CAM process of veneer fabrication. In order to ensure even and adequate reduction of the typodont, a putty index (Elite HD+ A-Silicone, Zirmack-Italy) was produced for the selected maxillary central incisor acrylic tooth before preparation. Feather edge veneer design was selected in which the facial surface preparation was terminated at the incisal edge without incisal reduction. A standard labial reduction was achieved with $0.3 \mathrm{~mm}$ depth for the cervical half and $0.5 \mathrm{~mm}$ for the incisal half of the labial surface through using three-wheel diamond depth cutters $0.3 \mathrm{~mm}$ and $0.5 \mathrm{~mm}$ sequentially (Brassler, USA). 
The remaining tooth structure between the depth orientation grooves was removed using a roundend tapered diamond stone (MANI-DIA-BursJapan). The preparation was extended proximally just before the contact area. The labial preparation was completed with this tapered diamond, while its tip established the $0.3 \mathrm{~mm}$ cervical chamfer finish line $0.5 \mathrm{~mm}$ short of the proposed cemento-enamel junction of the acrylic tooth (Figure 1). Finishing of the preparation was done using diamond finishing stones. The sectioned silicone index was used to ensure even reduction. Polishing of the preparation was performed using nylon bristle polishing brush and polishing paste.

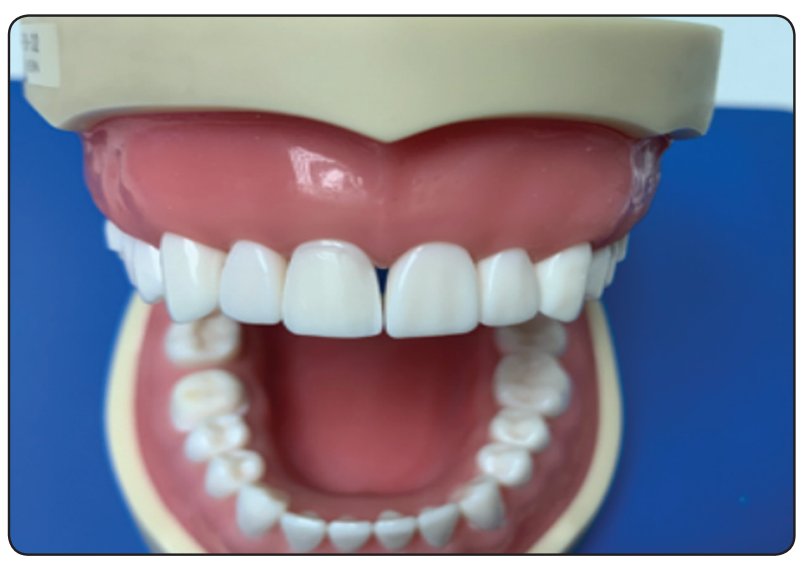

Fig. (1) Laminate veneer preparation of maxillary central incisor.

\section{II) Veneer fabrication procedure:}

Thirty ceramic veneers were constructed using IPS e.max CAD (IvoclarVivadent, Schaan, Liechtenstein). The restorations construction followed the standard three phases of CAD/CAM process. The scan phase was accomplished using extra-oral scanner "in-Eos X5 scanner" (Sirona dental, Bensheim, Germany). Two scanning procedures were done, one for the original typodont to obtain a bio-copy reference of the unprepared acrylic tooth. The second scan was done to capture digital impression of the prepared tooth. Virtual images of both scans were automatically correlated to aid in restoring the original tooth anatomy during the design phase. The designing phase of the veneers was completed using "Cerec Premium S.W 4.2.5" software. In this phase, veneer parameter was set for $0.5 \mathrm{~mm}$ for minimum veneer thickness and $30 \mu \mathrm{m}$ spacer thickness. Scanning and design were accomplished by the same clinician. Once the design was optimized, it was electronically sent to the milling unit "Cerec MCXL Premium" (Sirona dental, Bensheim, Germany). According to the selected milling protocol, the veneers were divided into three groups: Group 1: Ten veneers constructed using the normal (conventional) milling protocol, Group 2: Ten veneers constructed using the fast milling protocol, and Group 3: Ten veneers constructed using the two-step milling protocol (Figure 2).

Approximate milling time of ceramic laminates of the three groups was as follows: 8 minutes for the normal milling protocol, 5 minutes for the fast milling protocol and 16 minutes for the two-step milling protocol.

After the milling procedure, the veneers were crystallized following the manufacturer's instruction at temperature of $840^{\circ} \mathrm{C}$ and the dwell time of 7 minutes to give the glass-ceramic its final strength and esthetic properties. Glazing then followed using IPS e.max Ceram Glaze Paste (Ivoclar-Vivadent, Schaan, Liechtenstein) with a standard cooling procedure. Finally, the fit of the veneers was verified on the master preparation (Figure 3).

\section{III) Vertical marginal gap measurement:}

For proper assessment of the vertical marginal gap, the veneers were fixed on the master die using one drop of Te-Econom Bond adhesive (IvoclarVivadent) placed centrally in order to ensure adequate yet reversible binding between the die and veneers to stabilize the veneers in their place during the measuring procedure. ${ }^{(23)}$ 


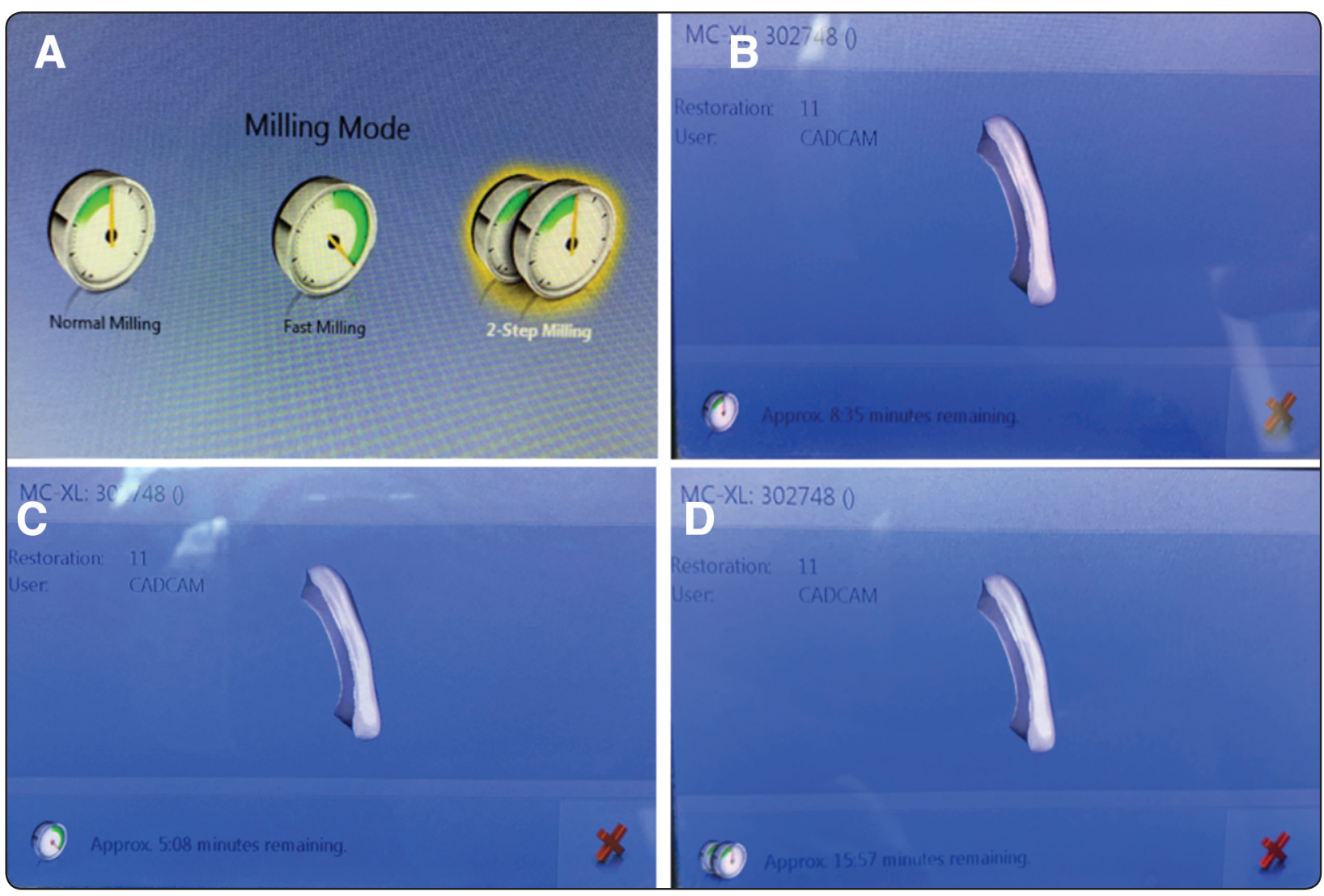

Fig. (2) The three tested milling protocols (A), the proposed milling time for the normal milling mode [8.35mins] (B), fast milling mode time [5.08 mins] (C), and the two-step milling mode time [15.57 mins] (D).

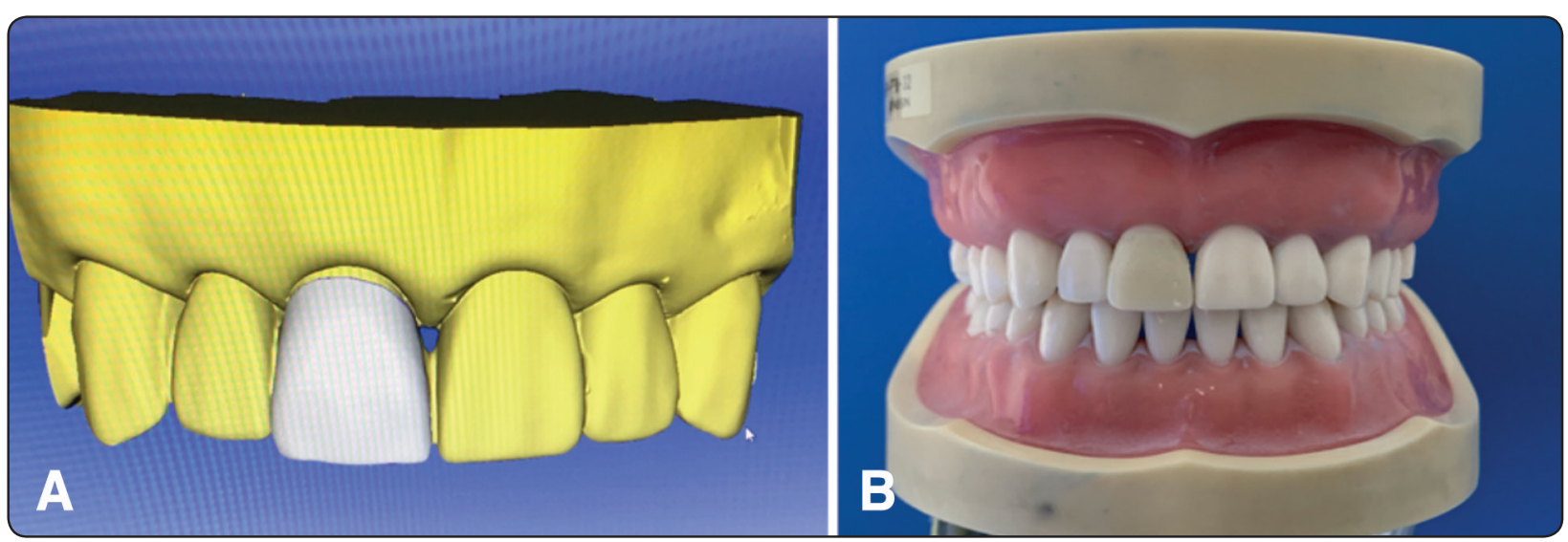

Fig. (3) Virtual design of the labial veneer (A), the milled veneer seated on the master preparation (B) 
Each veneer was photographed using measuring Stereomicroscope (Nikon Eclips E600, Tokyo, Japan) connected with an IBM compatible personal computer using a fixed magnification of X 45 . A digital image analysis system (Image J 1.43U, National Institute of Health, USA) was used for assessing and evaluating vertical marginal gap width. In this digital software, the measured parameters were expressed in pixels, thus system calibration was done to convert the pixels into real absolute world units. Calibration was done by comparing an object of known size with a scale generated by the image software. Shots of the margins were taken for each veneer. Marginal gap was measured as the vertical distance between finish line of the preparation and the ceramic veneer margin.

The measurements were done along the peripheral circumference for all the veneer margins (mesial, distal, cervical and incisal). Measurement at each point was repeated five times. Then the data obtained were collected, tabulated and then subjected to statistical analysis.

\section{RESULTS}

\section{Repeated measures ANOVA results: (Table 1)}

The obtained results showed that milling protocol (regardless of surface), surface (regardless of milling protocol) as well as the interaction between the two variables had a statistically significant effect on mean marginal gap. Since the interaction between the variables is statistically significant, so the variables are dependent upon each other.

\section{Effect of milling technique regardless of surface: (Table 2)}

Regardless of surface; there was a statistically significant difference between the milling protocols (P-value $<0.001$, Effect size $=0.625)$. Pair-wise comparisons between the protocols revealed that there was no statistically significant difference between normal and fast milling techniques; both showed the statistically significant highest mean marginal gap distances. Two-step milling technique showed the statistically significant lowest mean marginal gap distance.

TABLE (1) Repeated measures ANOVA results for the effect of different variables on mean marginal gap

\begin{tabular}{ccccccc}
\hline Source of variation & $\begin{array}{c}\text { Type III Sum } \\
\text { of Squares }\end{array}$ & df & $\begin{array}{c}\text { Mean } \\
\text { Square }\end{array}$ & F-value & P-value & $\begin{array}{c}\text { Effect size (Partial } \\
\text { eta squared) }\end{array}$ \\
\hline Milling protocol & 1023.5 & 2 & 511.728 & 14.976 & $<0.001^{*}$ & 0.625 \\
Surface & 684.608 & 3 & 228.203 & 8.725 & $<0.001^{*}$ & 0.326 \\
Milling protocol x Surface interaction & 526.157 & 6 & 87.693 & 3.353 & $0.007^{*}$ & 0.271 \\
\hline
\end{tabular}

df: degrees of freedom $=(n-1), *$ : Significant at $P \leq 0.05$

TABLE (2) The mean ( $\mu \mathrm{m})$, standard deviation (SD) values and results of repeated measures ANOVA test for comparison between marginal gap of different milling techniques regardless of surface

\begin{tabular}{|c|c|c|c|c|c|c|c|}
\hline \multicolumn{2}{|c|}{ Normal milling } & \multicolumn{2}{c|}{ Fast milling } & \multicolumn{2}{c|}{ Two-step milling } & \multirow{2}{*}{ P-value } & $\begin{array}{c}\text { Effect size (Partial eta } \\
\text { squared) }\end{array}$ \\
\cline { 1 - 5 } Mean & SD & Mean & SD & Mean & SD & & 0.625 \\
\hline
\end{tabular}

*: Significant at $P \leq 0.05$, Different superscripts are statistically significantly different 
Effect of surface regardless of milling technique: (Table 3)

Regardless of milling technique; there was a statistically significant difference between the surfaces (P-value <0.001, Effect size $=0.326$ ). Pair-wise comparisons between the surfaces revealed that the distal surface recorded the highest mean marginal gap distance with non-statistically significant difference from incisal and mesial surface and with a statistically significant higher mean measurement than the cervical surface which recorded the lowest mean marginal gap distance.

\section{Effect of different interactions on marginal gap: (Table 4 and Figure 4)}

Comparison between milling protocols:

At the cervical surface; there was a statistically significant difference between the milling protocols $(\mathrm{P}$-value $=0.009$, Effect size $=0.409)$. Pair-wise comparisons between the protocols revealed that fast milling protocol showed the statistically significant highest mean marginal gap. Normal milling protocol showed statistically significant lower mean value than fast milling. Two-step milling protocol showed the statistically significant lowest mean marginal gap distance.

At the incisal surface; there was no statistically significant difference between the three protocols $(\mathrm{P}$-value $=0.847$, Effect size $=0.018)$.

At the mesial and distal surfaces; there was a statistically significant difference between the milling protocols. Pair-wise comparisons between the protocols revealed that there was no statistically significant difference between normal and fast milling protocols; both showed the statistically significantly highest mean marginal gap distances. Two-step milling protocol showed the statistically significant lowest mean marginal gap distance.

\section{Comparison between surfaces:}

With normal milling; there was a statistically significant difference between the surfaces (P-value $=0.001$, Effect size $=0.622$ ). Pair-wise comparisons between the surfaces revealed that there was no statistically significant difference between mesial and distal surfaces; both showed the statistically significant highest mean marginal gap distances. There was no statistically significant difference between cervical and incisal surfaces; both showed the statistically significant lowest mean marginal gap distances.

With fast milling; there was a statistically significant difference between the surfaces (P-value $=0.032$, Effect size $=0.413)$. Pair-wise comparisons between the surfaces revealed that distal surface showed the statistically significant highest mean marginal gap distance. There was no statistically significant difference between cervical, incisal and mesial surfaces; all showed the statistically significant lowest mean marginal gap distances.

With two-step milling; there was no statistically significant difference between the surfaces (P-value $=0.133$, Effect size $=0.288$ ).

TABLE (3) The mean $(\mu \mathrm{m})$, standard deviation (SD) values and results of repeated measures ANOVA test for comparison between marginal gap distances at different surfaces regardless of milling technique

\begin{tabular}{|c|c|c|c|c|c|c|c|c|c|}
\hline \multicolumn{2}{|c|}{ Cervical } & \multicolumn{2}{c|}{ Incisal } & \multicolumn{2}{c|}{ Mesial } & \multicolumn{2}{c|}{ Distal } & \multirow{2}{*}{ P-value } & $\begin{array}{c}\text { Effect size (Partial } \\
\text { eta squared) }\end{array}$ \\
\cline { 1 - 6 } Mean & SD & Mean & SD & Mean & SD & Mean & SD & & 0.326 \\
\hline $34 \mathrm{AB}$ & 6.5 & $37.2 \mathrm{AB}$ & 4.6 & $39.7 \mathrm{~A}$ & 6.4 & $41.6 \mathrm{~A}$ & 8.6 & $<0.001^{*}$ & 0.6 \\
\hline
\end{tabular}


TABLE (4) The mean $(\mu \mathrm{m})$, standard deviation (SD) values and results of repeated measures ANOVA test for comparison between marginal gap distance measurements of the different protocols and surfaces

\begin{tabular}{|c|c|c|c|c|c|c|c|c|}
\hline \multirow[b]{2}{*}{ Surface } & \multicolumn{2}{|c|}{ Normal milling } & \multicolumn{2}{|c|}{ Fast milling } & \multicolumn{2}{|c|}{ Two-step milling } & \multirow{2}{*}{$\begin{array}{l}\text { P-value } \\
\text { (Between } \\
\text { technique) }\end{array}$} & \multirow{2}{*}{$\begin{array}{c}\text { Effect size } \\
\text { (Partial eta } \\
\text { squared) }\end{array}$} \\
\hline & Mean & $\mathrm{SD}$ & Mean & $\mathrm{SD}$ & Mean & $\mathrm{SD}$ & & \\
\hline Cervical & $33.2 \mathrm{BE}$ & 5.6 & $39.3 \mathrm{AE}$ & 3.7 & $29.4 \mathrm{C}$ & 6.2 & $0.009^{*}$ & 0.409 \\
\hline Incisal & $37.3 \mathrm{E}$ & 5.1 & $37.9 \mathrm{E}$ & 4.7 & 36.4 & 4.7 & 0.847 & 0.018 \\
\hline Mesial & $44.2 \mathrm{AD}$ & 5.8 & $40.5 \mathrm{AE}$ & 2.3 & $34.4 \mathrm{~B}$ & 6.3 & $0.007 *$ & 0.421 \\
\hline Distal & 45.2 AD & 6.9 & 46.9 AD & 3.7 & $32.6 \mathrm{~B}$ & 6.7 & $<0.001^{*}$ & 0.572 \\
\hline $\begin{array}{l}\text { P-value (Between } \\
\text { surfaces) }\end{array}$ & \multicolumn{2}{|c|}{$0.001 *$} & \multicolumn{2}{|c|}{$0.032 *$} & \multicolumn{2}{|c|}{0.133} & & \\
\hline $\begin{array}{c}\text { Effect size (Partial eta } \\
\text { squared) }\end{array}$ & \multicolumn{2}{|c|}{0.622} & \multicolumn{2}{|c|}{0.413} & \multicolumn{2}{|c|}{0.288} & & \\
\hline
\end{tabular}

*: Significant at $P \leq 0.05$

$A, B, C$ superscripts in the same row indicate statistically significant difference between techniques

$C, D, E$ superscripts in the same column indicate statistically significant difference between surfaces

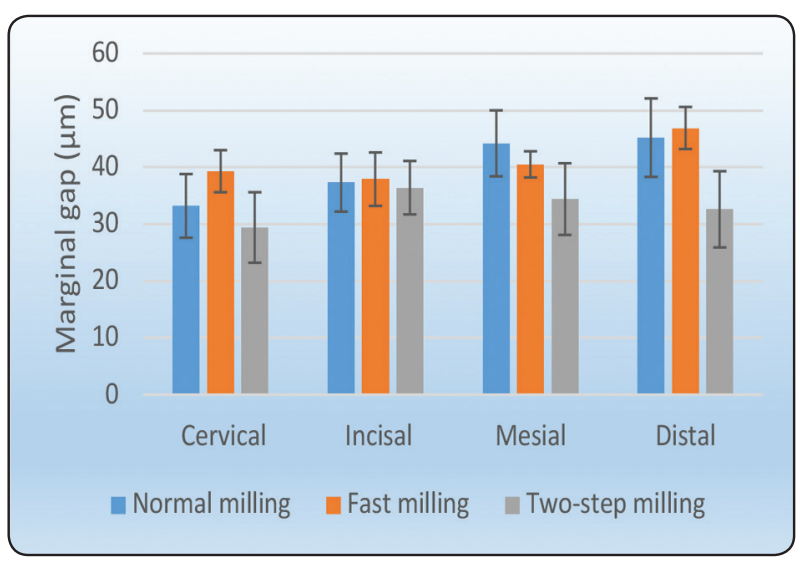

Fig. (4). Bar chart representing mean and standard deviation values for marginal gap distances of the three milling protocols at each surface

\section{DISCUSSION}

According to the results of the present investigation, the null hypothesis stating that there would be no difference concerning the marginal accuracy among the three milling protocols had to be rejected since there was a statistically significant difference between the milling protocols .Statistical analysis revealed that both the normal and fast milling protocols showed statistically significant highest mean marginal gap distances while the twostep milling protocol showed statistically significant lowest mean marginal gap distance.

Ceramic laminate veneers are considered among the most conservative approaches to solve many cases having problems in shape, color or alignment of anterior teeth. ${ }^{(24,25)}$

Lithium disilicate ceramic represents the most preferable material for fabrication of this type of thin and brittle restorations owing to their excellent 
esthetic and satisfactory mechanical properties. They can be processed using either heat pressing techniques (IPS e.max Press) or CAD/CAM milling procedures (IPS e.max CAD). ${ }^{(26)}$

Machining of this type of delicate restorations always represents a challenge to the dental personnel specially at critical areas as thin margins. New milling options have been introduced in recent softwares to maximize milling accuracy of ceramic restorations and suit different restoration thicknesses and designs. Since the effect of these milling options on marginal integrity of thin restorations has not been investigated yet, thus this study was conducted to highlight this point of research on laminate veneers with minimal ceramic thickness.

In the current research, a typodont tooth resembling maxillary central incisor was used as it represents the most common tooth in the dental arch restored with laminate veneer. Selection of artificial acrylic tooth was done to overcome any variations in natural teeth which might affect the design and thickness of the restoration ${ }^{(27,28)}$

In order to duplicate the original tooth contour, a primary scan was obtained for the unprepared tooth to serve as a biocopy reference which was later added to the software during the $\mathrm{CAD} / \mathrm{CAM}$ procedure to aid in restoration design. ${ }^{(28,29)}$ Every effort was done to ensure adequate and even amount of reduction using putty index and depth cutter burs. ${ }^{(27)}$ The typodont preparation followed the guidelines for veneer preparation as stated by many authors to keep the preparation confined within enamel and at the same time ensure enough thickness to provide adequate fracture resistance and proper translucency. ${ }^{(30)}$

The three milling protocols used in the present study were normal, fast and two step milling procedures. Their selection was based on time factor needed for completion of milling procedure and on the options given by recent software used. The aim was to investigate their effect on the marginal integrity of delicate thin margins of laminate veneer which is considered as an important criterion for success and longevity of the restoration. ${ }^{(31)}$

Marginal integrity in the current study was assessed by measuring the vertical marginal gap as it is considered as the most frequently used method to examine fitting accuracy of the restoration. ${ }^{(32,33)}$ A high accuracy stereomicroscope was used as a direct view assessment method offering numerous advantages like convenience, accuracy, easiness and speed of use as well as retrievability of restoration unlike other destructive procedures as sectioning method. ${ }^{(34)}$

Our scope during this study was to examine the sole effect of individual milling protocols on primary precision of the laminate veneers, thus measurements were made without cementation to exclude variations resulting from properties of cement and cementation technique. ${ }^{(35-37)}$

Measurements were taken along the peripheral circumference for each surface of the veneer (Mesial, labial, distal, and incisal) to obtain an overall picture about the restoration accuracy and seating.

Results of previous researches reported a wide range of vertical marginal gap for laminate veneer restorations, however many articles stated that a marginal gap of $120 \mu \mathrm{m}$ or less is considered as clinically acceptable. ${ }^{(38-41)}$ Since the marginal results of all groups in the current study ranged from 29.4 $\mu \mathrm{m}$ to $46.9 \mu \mathrm{m}$, thus they fell within the clinically acceptable range.

Statistical analysis of the results concerning the effect of milling protocols on marginal accuracy revealed significant difference between them. Two-step milling technique showed the lowest mean marginal gap distance while both normal and fast milling techniques showed the highest mean marginal gap distances. It was apparently logic to obtain these results as the manufacturer 
demonstrated that two step milling of thin delicate restorations as veneers passes by two stages. The first milling stage is concerned with bulk removal of excess material through fast mill followed by milling at regular speed to obtain fine details of the restoration and this explains the superior marginal accuracy of the restoration compared to the other milling protocols. ${ }^{(22)}$ Since our study was one of its kind using different milling protocols, thus the obtained results were hard to compare with previous or similar studies.

In addition to this, regarding the time taken for each milling protocol, the two step milling lasted approximately double the time needed for the normal milling which might explain the significant difference between them as regards to marginal accuracy .

Irrespective to the milling protocol; the marginal gap distance at the cervical surface recorded the lowest mean marginal gap distance while the distal, incisal and mesial surfaces had the highest mean marginal gap distance. These results were in agreement with previous studies ${ }^{(27,42)}$ which postulated that the least adaptation was incisally. This can be explained by the fact that the margins are thinner incisally, thus more liable for chipping causing gap formation. Also, during milling procedure, the diameter of the cutting tool might be larger than some parts of thin tooth preparations limiting access of the cutting tool to narrow regions as incisal edges leading to incisal misfit. ${ }^{(27)}$ Another explanation might be attributed to lack of incisal edge preparation making it difficult to properly seat the laminate veneer specially in incisal area. ${ }^{(43)}$

However, these results were inconsistent with other studies ${ }^{(44)}$ showing that the smallest mean vertical gap was noted at the incisal surface, this controversy might be attributed to differences in preparation design, ceramic type and CAD/CAM system used.

A point of concern was whether similar marginal gap values could be achieved if more complicated restoration designs or different materials were selected in this study. Nevertheless, it was the effect of milling protocols on delicate restorations that was of interest for our present study.

One of the limitations of this study was the utilization of an acrylic typodont instead of natural teeth as well as lack of cementation although justification for this was previously discussed. Additional studies must be carried out considering different experimental conditions.

\section{CONCLUSIONS}

Within the limitations of this in-vitro study, the following conclusions were drawn:

1) Marginal discrepancy of all groups fell within the clinically acceptable value; thus, the three milling protocols can be safely used.

2) Veneers fabricated using the two-step milling protocol exhibited the least marginal discrepancy among other experimental groups, thus it can be used as the protocol of preference if restoration accuracy is of utmost importance

3) Since there was no significant difference between normal and fast milling protocols regarding marginal discrepancy, thus fast milling can be recommended for veneer fabrication if chairside time is of prime importance in some cases.

4) Cervical marginal discrepancy was observed to have the least value compared to other surfaces

\section{REFERENCES}

1. Barizon KT, Bergeron C, Vargas MA, Quian F,Cobb DS,Gratton DG and Geraldeli S: Ceramic materials for porcelain veneers: part II. Effect of material, shade, and thickness on translucency. J Prosthet Dent 2014;112:864870

2. Denry I and Holloway J: Ceramics for dental applications: a review. Materials 2010;3:351-368

3. Anadioti E, Aquilino SA, Gratton DG , Holloway GA, Denry IL,Thomas GW and Kian F: Internal fit of pressed 
and computer-aided design/computer-aided manufacturing ceramic crowns made from digital and conventional impressions. J Prosthet Dent 2015;113:304-309

4. Celik C and Gemalmaz D: Comparison of marginal integrity of ceramic and composite veneer restorations luted with two different resin agents: an in vitro study. Int J Prosthodont 2002;15:59-64

5. Peumans M, Van Meerbeek B, Lambrechts $P$ and Vanherle G: Porcelain veneers: a review of the literature. J Dent 2000;28:163-177

6. Beschnidt SM and Strub JR: Evaluation of the marginal accuracy of different all-ceramic crown systems after simulation in the artificial mouth. J Oral Rehabil 1999; 26:582-593

7. Boitelle P, Mawussi B, Tapie L and Fromentin O: A systematic review of CAD/CAM fit restoration evaluations. J Oral Rehabil 2014;41:853-874

8. Omar H, Atta O, El-Mowafy O and Khan SA: Effect of CAD-CAM porcelain veneers thickness on their cemented colour. J of Dent 2010;38:95-104.

9. Xing W, Jiang T, Ma X, Liang S, Wang Z, Sa Y and Wang $\mathrm{Y}$ :Evaluation of the esthetic effect of resin cements and try-in pastes on ceromer veneers. J of Dent 2010;38(Suppl. 2):87-94.

10. ALGhazali N, Laukner J, Burnside G, Jarad F, Smith P and Preston A: An investigation into the effect of try-in pastes, uncured and cured resin cements on the overall color of ceramic veneer restorations: an in vitro study. J of Dent 2010;38(Suppl. 2):78-86.

11. Sedanur T and Bora B: Colour stability of laminate veneers: an in vitro study. J of Dent 2011;39 (Suppl. 3):57-64

12. Celik C and Gemalmaz D: Comparison of marginal integrity of ceramic and composite veneer restorations luted with two different resin agents: an in vitro study. Int J of Prosthodont 2002;15:59-64.

13. Tu“rk AG, Sabuncu M and U“" nal S: Comparison of the marginal adaptation of direct and indirect composite inlay restorations with optical coherence tomography. J Appl Oral Sci 2016;24:383-390

14- Wolfart S, Wegner SM, Al-Halabi A and Kern M: Clinical evaluation of marginal fit of a new experimental all-ceramic system before and after cementation. Int $\mathrm{J}$ Prosthodont 2003;16:587-592.
15. Iwai T, Komine F, Kobayashi K, Saito A and Matsumura $\mathrm{H}$ : Influence of convergence angle and cement space on adaptation of zirconium dioxide ceramic copings. Acta Odontol Scand 2008;66:214-218.

16. Endera and Mehl A : In vitro evaluation of the accuracy of conventional and digital methods of obtaining full arch dental impressions. Quintessence Int 2015;46:9-17

17. Zielgler M : Digital impression taking with reprodcibly high precision. Int Comput Dent 2009; 12:159-163

18. Mehl A: A new concept for the integration of dynamic occlusion in the digital construction process. Int J Comput Dent 2012;15:109-123

19. Kirsch C , Ender A, Attin T and Mehl A : Trueness of four different milling procedures used in dental CAD/CAM systems clinical oral investigations 2017;21:551-558

20. Giannetopoulos S , van Noort R and Tsitrou E : Evaluation of the marginal integrity of ceramic copings with different marginal angles using two different CAD/CAM systems) J of Dent 2010: 580-586

21. Miyazaki T, Hotta Y, Kunii J, Kuriyama S and Tamaki Y: A review of dental CAD/CAM: current status and future perspectives from 20 years of experience. Dent Mater J 2009;28(1):44-56.

22. CEREC Premium Software Version 4.5.X. Operator's manual . Sirona Dental Systems 8.2017.

23. Soares CJ, Martins LRM and Ferandes AJ: Marginal adaptation of in direct composites and ceramic Inlay systems. Oper Dent 2003; 28-6: 689-694.

24. Calamia JR and Calamia CHS: Ceramic laminate veneers: reasons for 25 years of success. Dent Clinics of North America 2007;51:399-417.

25. Chen JH, Shi CX, Wang M, Zhao SJ and Wang H: Clinical evaluation of 546 tetracycline-stained teeth treated with porcelain laminate veneers. J of Dent 2005;33:3-8.

26. Tysowski GW. The science behind lithium disilicate: A metal-free alternative. Dentistry Today 03/01/2009.

27. Aboushelib MN, Elmahy WA and Ghazy MH: Internal adaptation, marginal accuracy and microleakage of a pressable versus a machinable ceramic laminate veneers. J of Dent 2012; 40: $670-677$.

28. Najim BAE and Al-Rawi II:The Influence of Different Fabrication Techniques and Preparation Designs on the Marginal Adaptation of Ceramic Veneers (An In vitro Comparative Study).J Bagh College Dentistry, 2015; 27 (4):8-14. 
29. Abdul Khaliq AGH and Al-Rawi II: Fracture Strength of Laminate Veneers using Different Restorative Materials and Techniques (A Comparative in Vitro Study). J BaghColl Dentistry 2014; 26 (4): 1-8.

30. LeSage BP: Establishing a Classification System and Criteria for Veneer Preparations, Continuing Education Veneer Treatment Classification Table. Compendium. 2013; 34 (2).

31. Pedroche LO, Bernardes SR, Leão MP, Kintopp CCD, Correr GM, Ornaghi BP and Gonzaga CC: Marginal and internal fit of zirconia copings obtained using different digital scanning methods. J Braz Oral Res, 2016; 30(1).

32. Groten M, Girthofer S and Pro “bster L.:Marginal fit consistency of copy-milled all-ceramic crowns during fabrication by light and scanning electron microscopic analysis in vitro. J Oral Rehabil 1997;24:871-81.

33. Petteno D, Schierano G, Bassi F, Bresciano ME and Carossa S : Comparison of marginal fit of three different metal ceramic systems: An in vitro study. International J of prosthodontics2000;13: 405-408

34. Sorensen JA: A standardized method for determination of crown margin fidelity. J of Prosthet Dent 1990;64: 18-24

35. Tinschert J, Natt G, Mautsch W, Spiekermann H, and Anusavice KJ: Marginal Fit of Alumina and Zirconia Based Fixed Partial Dentures Produced by a CAD/CAM System. Oper Dent 2001; 26: 367-374.

36. Yeo IS, Yang JH and Lee JB: In vitro marginal fit of three all ceramic crown systems. J of Prosthet Dent 2003; 90:459-464

37. Shillingberg HT, Hobo S and Fisher TW : Preparation design and margin distortion in porcelain-fused-to-metal restorations. J of Prosthet Dent 2003;89:527-532.
38. BeuerF, Richter $\mathbf{J}$ and Gernet W.:Influence of preparation angle on marginal and internal fit of CAD $\backslash C A M$ fabricated Zirconia crown coping. J. Quintessence Inte, 2009; 40 (3): 443-450.

39. Borba M, Miranda Jr, Cesar PF, Griggs JA and Della Bona A: Evaluation of the adaptation of zirconia-based fixed partial dentures using micro-CT technology. J Braz Oral Res 2013; 27 (5):396-402

40. Al-Zubaidi ZAK, and Al-Shamma AMW: The effect of different finishing lines on the marginal fitness of full contour zirconia and glass ceramic CAD/CAM crowns (An in vitro study). J Dent Mater Tech, 2015; 4 (3): 127-136.

41. Majeed MA, Al-Adel SK: Evaluation of the marginal and internal fitness of full contour CAD/CAM crowns made from zirconia, lithium disilicate, zirconia-reinforced lithium silicate and hybrid dental ceramic by silicone replica technique (A comparative In vitro study).J of Genetic and Environ Res Conservation, 2016; 4 (1):10-20.

42. Suh PS, Johnson R and White SN: Fit of veneers made by CAD-CAM and platinum foil methods.Operat dent, 1997;22:121-7.

43. Da Cunha LF, Pedroche LO, Gonzaga CC and Furuse AY : Esthetic, occlusal, and periodontal rehabilitation of anterior teeth with minimum thickness porcelain laminate veneers. J Prosthet Dent 2014;112:1315-1318.

44. Lin TM, Liu PR, Ramp LC, Essig ME, Givan DA and Pan YH: Fracture resistance and marginal discrepancy of porcelain laminate veneers influenced by preparation design and restorative material in vitro. J of Dent 2012;4: 202-209. 